\title{
Serbia: Another endemic region for canine ocular thelaziosis"1)
}

\author{
MILAN HADŽI-MILIĆ, TAMARA ILIĆ*, PREDRAG STEPANOVIĆ**, \\ JELENA ĐORĐEVIĆ, SANDA DIMITRIJEVIĆ*
}

\begin{abstract}
Department of Surgery, Orthopaedic and Ophthalmology, *Department of Parasitology,
**Department of Equine, Small Animal, Poultry, and Wild Animal Diseases, Faculty of Veterinary Medicine, University of Belgrade, Bulevar Oslobođenja 18, Belgrade, Serbia
\end{abstract}

\section{Hadži-Milić M., Ilić T., Stepanović P., Đorđević J., Dimitrijević S. Serbia: Another endemic region for canine ocular thelaziosis}

\section{Summary}

Canine thelaziosis is widely distributed in Far Eastern countries and considered endemic in many European countries, between latitudes $39^{\prime}$ and $46^{\prime} \mathrm{N}$. Because of the unique relationship between the causer and its intermediate and final hosts, the genus Thelazia is one of the most specialized nematodes in the taxon. Thelazia callipaeda (superfamily: Thelazioidea) infects the conjunctivas of several mammalians, including dogs and humans. Since dogs may also represent a reservoir of infection for humans, the aim of the study was to show the epidemiological situation of thelaziosis in dogs in the Republic of Serbia, after it was first diagnosed in 2014, which is crucial for the successful treatment, control, and prevention of the disease. The research was performed on privately owned dogs in the period from the end of April 2013 to the end of October 2015 in 7 different regions in Serbia. Adult parasites were mechanically removed from dogs with manifested ocular disorders, and thelaziosis was diagnosed in 178 out of 501 animals. The high prevalence of T. callipaeda in dogs $(35.52 \%)$ in the analyzed areas of Serbia indicates the endemicity of eyeworm infestation in these areas.

Keywords: dog, moxidectin, Serbia, Thelazia callipaeda

Sixteen species of the genus Thelazia parasitic nematodes (Spirurida: Thelaziidae) have been reported to infect bovines, equines, canines, felines and humans, causing eye infections (31) in Europe, Asia, North America, South America, and South Africa.

T. callipaeda (33) and T. californiensis (32) are parasites of the conjunctival sac and nasolacrimal duct in dogs, cats, rabbits, foxes, and humans (1). Thelazia californiensis occurs in western areas of the United States, whereas Thelazia callipaeda is distributed in Far Eastern countries and throughout Europe (36). The first evidence of Thelazia callipaeda was from Asian countries $(3,34)$. In areas with the poorest hygienic conditions in this region, human infections with this nematode have shown a notable increase in the last two decades $(35,36)$.

Morphologically adult worms are creamy white, tread-like, up to $2 \mathrm{~cm}$ in length (12). Male adults are $4.5-13 \mathrm{~mm}$ in length and 0.25 to $0.75 \mathrm{~mm}$ in diameter, whereas females are longer, from 6.2 to $17 \mathrm{~mm}$, and from 0.3 to $0.85 \mathrm{~mm}$ in diameter (40). The anterior end is tapered, and the bluntly rounded posterior end

\footnotetext{
1) The work was funded by the Ministry of Education, Science and Technology Development of the Republic of Serbia.
}

is recurved ventrally. The body surface is covered with a heavily striated cuticle. The anterior extremity bears a conspicuous buccal capsule divided in festoons. The esophagus is essentially muscular, $0.47 \mathrm{~mm}$ long, and there is a conspicuous nerve ring. The male reproductive tube recurves distally and terminates near the esophago-intestinal junction. There are numerous paired perianal papillae surrounding the cloacal opening and paired unequal spicules. The right spicule is short and measures $0.14 \mathrm{~mm}$; the left is slender and very long, measuring $0.94 \mathrm{~mm}$ (12). First-stage larvae $\left(\mathrm{L}_{1}\right.$, body lenght $0.31-0.4 \mathrm{~mm}$; body width $0.013-0.046 \mathrm{~mm}$ ) present a shell membrane (i.e. embryonated eggs) and are arranged in a row in the distal uterus of adult females (25). The dimensions of the other developmental stages of T. callipaeda are as follows: second-stage larvae $\left(\mathrm{L}_{2}\right)$ - body lenght 0.46 $-3.2 \mathrm{~mm}$, body width $0.055-0.070$ ), third-stage larvae $\left(\mathrm{L}_{3}\right)$ - body lenght 3.2-3.69 mm, body width 0.12-0.72 $\mathrm{mm})$, and the morphology of fourth-stage larvae $\left(\mathrm{L}_{4}\right)$ is not described (26).

The Thelazia nematodes have an indirect life cycle; the vectors play the role of an intermediate host. Intermediate hosts are the Diptera species of the family 
Drosophilidae (subfamily: Steganinae), which, besides fruit and tree sap, feed on ocular secretions of animals and humans (2). Intermediate hosts for T. callipaeda are Phortica variegata in Europe (21) and P. okadai in China (39). Otranto et al. (28) contend that Musca domestica is not a vector of T. callipaeda, either under natural or experimental conditions.

The transmission of canine thelaziosis occurs when the intermediate host, a drosophila fly of the genus Phortica, feeds on lacrimal secretions of infected dogs and ingests first-stage larvae $\left(\mathrm{L}_{1}\right)$ produced by adult females of $T$. callipaeda, which live together with males in the conjunctival sac. After being ingested by the fly, T. callipaeda larvae migrate in the vector's body (i.e. testis of the male) and undergo development from $\mathrm{L}_{1}$ to the infective, third-stage larvae $\left(\mathrm{L}_{3}\right)$ within 14-21 days. Following this migration, the $\mathrm{L}_{3}$ of Thelazia emerge from the labella of the infected fly. They are deposited on the eye as the vector feeds on lacrimal secretions and develop into dioecious adult stages in the ocular cavity within 35 days $(11,27)$.

Clinical manifestations resulting from the pathogenic action of the larvae and adult parasites include pruritus, lacrimation, congestion, epiphora, exudative conjunctivitis, corneal edema evolving to keratitis and corneal ulceration in severe cases (31). In dogs and cats, chronic conjunctivitis may lead to photophobia, blepharitis marginalis, lacrimation, corneal opacity, ulcerations, corneal perforation, and blindness (14).

The causative agents of canine thelaziosis ( $T$. callipaeda and T. californiensis) may infect humans. Human infections, mainly in children and the elderly, occur predominantly in rural communities with poor living conditions and low socioeconomic standards.

The aim of this study is to evaluate the prevalence of thelaziosis in the Republic of Serbia.

\section{Material and methods}

The research was performed on dogs in the Republic of Serbia from the end of April 2013 to the end of October 2015. In this period, thelaziosis was diagnosed in 178 out of 501 privately owned dogs with manifested ocular disorders. Of all positive dogs, 39 were from northern Serbia (North Banat District and Novi Sad suburbs, i.e. south Bačka District), 59 were from central Serbia (Belgrade suburbs and Braničevo District), and 68 were from eastern Serbia (Bor and Zaječar districts), and 12 from southern Serbia (Pčinja District) (Fig. 1). Infected dogs were of different breeds (mixed breeds, German Shepherd, Airedale Terrier, German Jagdterrier, Weimaraner, German Shorthaired Pointer, Samoyed, and other) and of both sexes. Their age ranged from 10 months to 13 years, they lived outdoors, and some were used for hunting. All animals were in good body condition, but were referred to the practice because of ocular discharge. The total prevalence of ocular manifestations amounted to $35.52 \%(178 / 501)$. The prevalence of mild ocular manifestacions (ocular discharge, follicular conjunctivitis and blepharospasm) was 32.53\% (163/501),

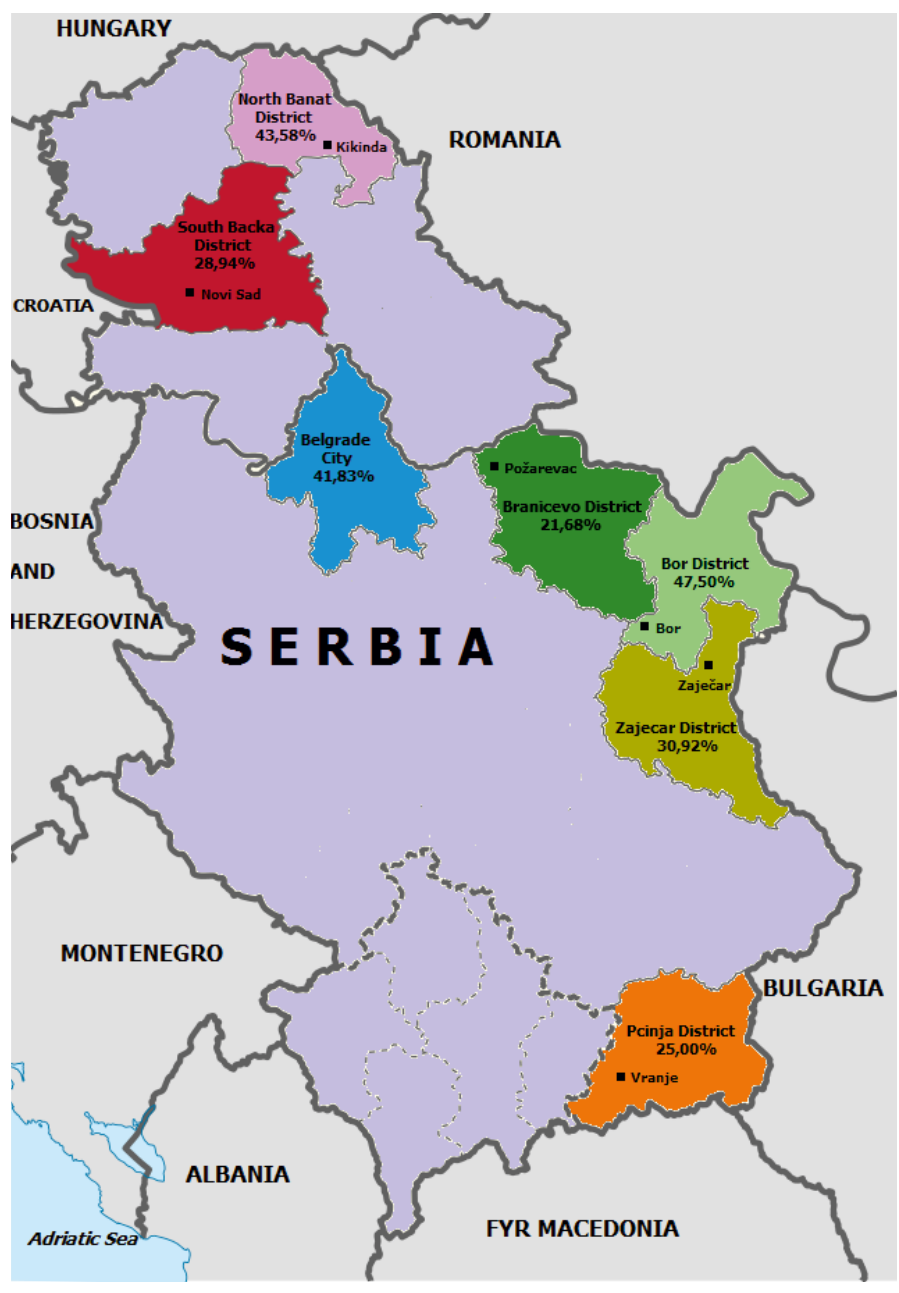

Fig. 1. The distribution of Thelazia callipaeda in Serbia

whereas severe signs of keratitis were observed in $2.99 \%$ (15/501) of the dogs (Fig. 2).

Adult parasites were removed mechanically with microsurgical instruments (suture-tying forceps without teeth) after eversion of the third eyelid. Depending on the number of parasites present and the patient's aggressiveness, the removal was performed under local anesthesia (bupivacain, tetracain), mild sedation (ketamin hydrochloride, diazepam) with local anesthesia or under general anesthesia (cevofluran, induced with propofol; ketamin). After the removal of

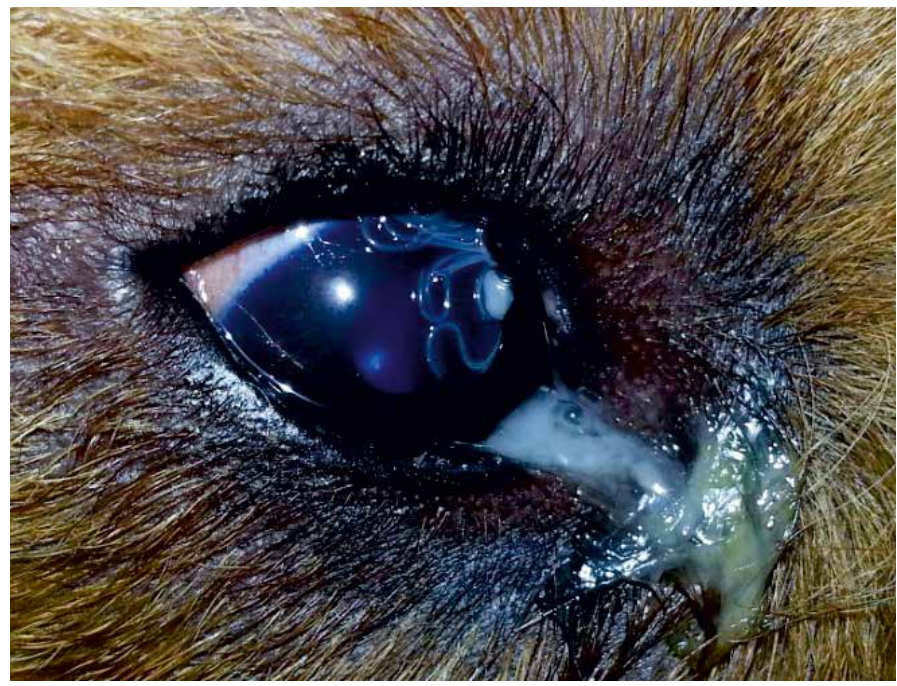

Fig. 2. Thelazia callipaeda in a dog's eye 


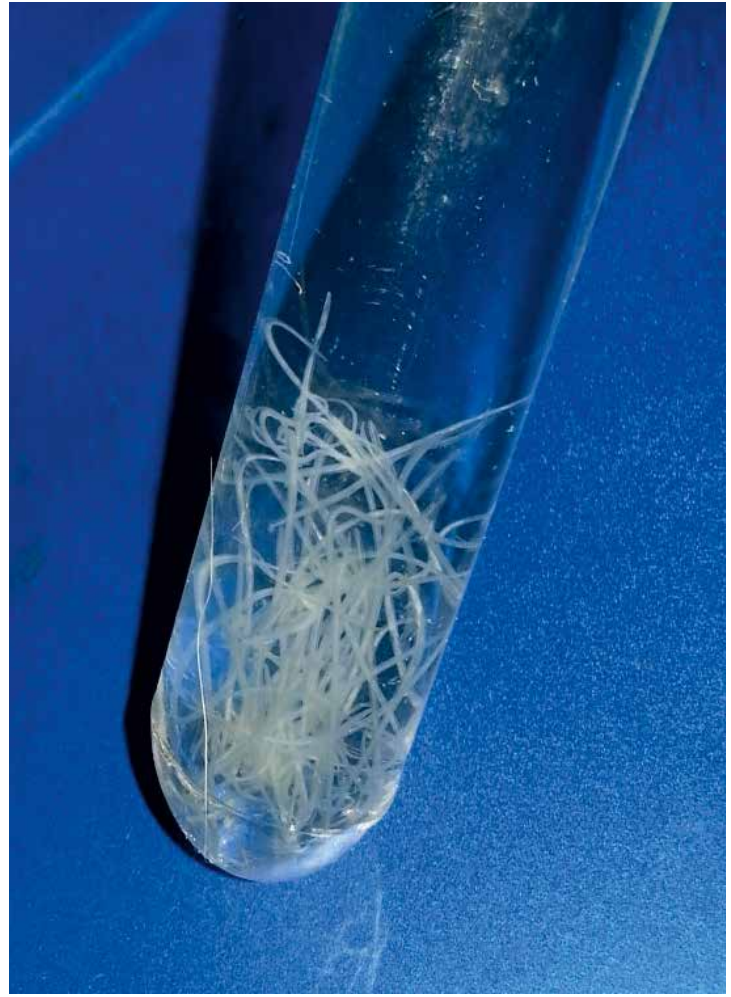

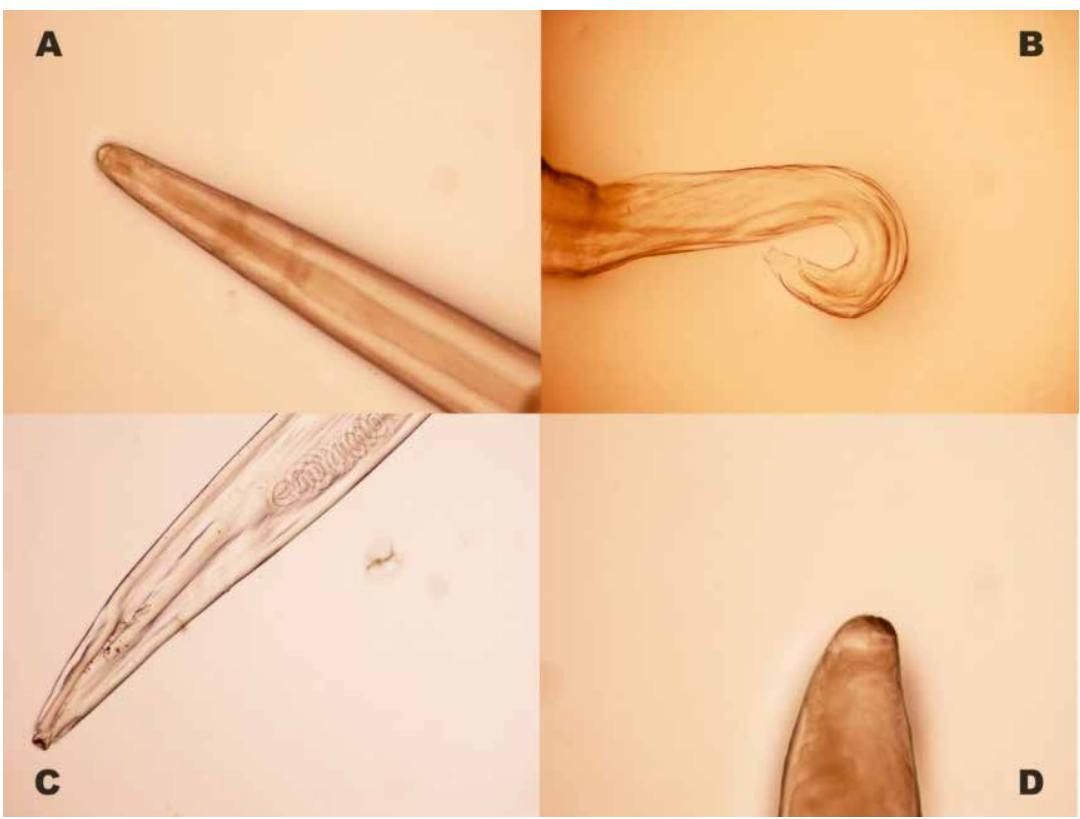

Fig. 4. A) Anterior portion of T. callipaeda (male), $\times 100$; B) Tail part of the male worm, $\times 100$; C) Anterior portion of T. callipaeda (female), $\times 100$; D) Tail part of the female worm, $\times \mathbf{4 0 0}$

Fig. 3. Adult parasites collected from an eye

the parasites from the conjunctival sac and after lavage, therapy was carried out with topical antibiotics (gentamicin was applied to 65 out of 178 dogs, tobramycin to 93 out of 178 , and ofloxacin to 44 out of 178 dogs), systemic antibiotic, and anti-inflammatory drugs (in 117 dogs with severe follicular conjunctivitis). When the removal procedure had been completed, antiparasitic treatment was performed. Ivermectin (s/c $0.2 \mathrm{mg} / \mathrm{kg}$ ) was used in 104 out of $178 \mathrm{dogs}$, and a spot-on solution of $100 \mathrm{mg}$ imidacloprid and $25 \mathrm{mg}$ moxidectin in 74 out of 178 dogs.

No adverse effects were observed in dogs treated with ivermectin, since breeds sensitive to ivemerctin had not been subjected to this therapeutic protocol.

Adult parasites collected from each dog were put in a vessel with saline solution $(0.9 \% \mathrm{NaCl})$ and then transferred to a test tube with saline solution (Fig. 3). After that, the parasites were well rinsed and prepared for identification by native preparation. They were placed on microscope slides with a few drops of glycerol and examined under a microscope.

Worms collected from each dog were identified morphologically (species and sex) according to keys proposed by Otranto et al. (29) Their sex was determined on the basis of the position of the vulva anterior to the esophagus-intestinal junction (females), the presence of five pairs of postcloacal papillae (males), and the number of cuticle stripes (Fig. 4).

Both adult and third-stage larval parasites were found in dogs with severe ocular changes. Third-stage larvae, after being washed out of the saccus conjunctivae, were identified by measurements, and their length ranged from the 3.3 to $3.5 \mathrm{~mm}(26)$.

\section{Results and discussion}

In the period from the end of April 2013 to the end of October 2015, T. callipaeda was diagnosed in $35.52 \%$
Tab. 1. Geographical distribution and prevalence of Thelazia callipaeda in dogs in Serbia

\begin{tabular}{|l|c|c|c|}
\hline \multicolumn{1}{|c|}{ Region } & $\begin{array}{c}\text { Number of } \\
\text { dogs examined }\end{array}$ & \multicolumn{2}{|c|}{$\begin{array}{c}\text { Thelazia callipaeda-infected } \\
\text { dogs }\end{array}$} \\
\hline North Banat District & 39 & 17 & 43.58 \\
\hline South Bačka District & 76 & 22 & 28.94 \\
\hline Belgrade City & 98 & 41 & 41.83 \\
\hline Braničevo District & 83 & 18 & 21.68 \\
Bor District & 80 & 38 & 47.50 \\
\hline Zaječar District & 98 & 30 & 30.92 \\
\hline Pčinja District & 48 & 12 & 25.00 \\
\hline Total & 501 & 178 & 35.52 \\
\hline
\end{tabular}

$(178 / 501)$ of the dogs examined in Serbia. The highest prevalence of ocular thelaziosis was found in the Bor District - 47.50\% (38/80 dogs examined), the North Banat District - 43.58\% (17/39 dogs examined) and the Belgrade suburbs $-41.83 \%$ (41/98 dogs examined) (Tab. 1).

Infected dogs showed different intensity of infection with adult forms of T. callipaeda. In 67.97\% (121/178) of the animals examined, up to 20 individual parasites were found. In $23.59 \%$ (42/178), 20-70 individual parasites were found, and in $8.42 \%(15 / 178)$ more than 70 individual parasites were found (Tab. 2).

The parasites collected from the infected dogs were counted to determine the infection rate. The number of worms collected per dog ranged from 1 (one female parasite only in one eye of one dog) to 78. Most dogs had a high infection rate (Fig. 2). The highest infection rate was detected in a 5-year-old male German shep- 
Tab. 2. Intensity of infection and location of Thelazia callipaeda nematodes in infected dogs in Serbia

\begin{tabular}{|l|c|c|c|c|c|c|c|}
\hline \multirow{2}{*}{ Region } & \multirow{2}{*}{$\begin{array}{c}\text { Number of } \\
\text { infected dogs }\end{array}$} & \multicolumn{3}{c|}{$\begin{array}{c}\text { Number of parasites diagnosed } \\
\text { in dogs' eyes }\end{array}$} & \multicolumn{4}{c|}{ Location of parasites } \\
& & $<20$ & $20-70$ & $>70$ & Right eye & Left eye & Both eyes \\
\hline North Banat District & 17 & 12 & 4 & 1 & 10 & 7 & - \\
South Bačka District & 22 & 13 & 8 & 1 & 5 & 14 & 3 \\
Belgrade City & 41 & 29 & 10 & 2 & 15 & 21 & 5 \\
Braničevo District & 18 & 15 & 2 & 1 & 9 & 3 & 6 \\
Bor District & 38 & 25 & 9 & 4 & 18 & 12 & 8 \\
Zaječar District & 30 & 22 & 5 & 3 & 6 & 13 & 11 \\
\hline Pčinja District & 12 & 5 & 4 & 3 & 7 & 5 & - \\
Total & 178 & 121 & 42 & 15 & 70 & 75 & 33 \\
\% & 100 & 67.97 & 23.59 & 8.42 & 39.32 & 42.13 & 18.54 \\
\hline
\end{tabular}

tion revealed the existence of seven distinct haplotypes of T. callipaeda in dogs, cats, and foxes in Asia, but only one haplotype in Europe. The finding of haplotype 1 (h1) of $T$. callipaeda in red foxes in Spain indicates the potential role of foxes as reservoirs for this Thelazia species (4). From the parasitological point of view, these results are very interesting because T. callipaeda has

herd living in Avala (Belgrade suburb), from whose eyes 78 adult parasites were collected ( 33 males and 45 females) - more from the left eye (Fig. 3, 4).

In most of the infected dogs $(75 / 178-42.32 \%)$, adults of $T$. callipaeda were found in the left eye. In $39.32 \%(70 / 178)$ of the dogs, thelasiosis affected the right eye, and $18.54 \%(33 / 178)$ of the dogs had nematodes in both eyes (Tab. 2). In dogs with small infection intensity, it was not necessary to collect the parasites mechanically, because they abandoned the conjunctival sack spontaneously after therapy. Since canine thelaziosis has epidemiological significance, the geographical distribution of Thelazia callipaeda is of great importance for successful treatment, control and prevention of this parasitosis.

Thelazia callipaeda is widely distributed in dogs, cats, and humans in the former Soviet republics, and, because it is widespread in Far Eastern countries (China, Korea, Myanmar, Japan, Indonesia, Thailand, Taiwan, and India), it is called the oriental eyeworm (1). Climate in the countries where T. callipaeda has been reported varies from tropical (Indonesia) and subtropical (Japan) in the Far East to temperate in the Russian Federation. In Europe, infections by T. callipaeda have been reported in Italy (25), Germany (9), Switzerland (14), France (34), Spain (16), Portugal $(13,38)$, Belgium (5), Serbia (18), and Romania (15).

Hodžić et al. (10) reported autochthonous cases of T. callipaeda infection in red foxes, dogs, and cats in Bosnia Herzegovina and in Croatia, and these findings suggest that thelaziosis could be present in other Balkan areas.

Gajić et al. (8) reported the first cases of autochthonous canine and feline thelaziosis in different localities in Serbia. Reports of thelaziosis in cats have been significantly rarer. The prevalence of infection by this Thelazia in cats is lower, since they are less exposed to the population of intermediate hosts $(17,25,37)$.

In the wild animal population, T. callipaeda was recorded in wolves (20), and a little later it was also diagnosed for the first time in wild cats, ferrets, and brown rabbits (23). A thorough molecular examina- the largest number of direct host species of all Thelazia species, which are mostly host-specific (1).

Seasonality in the reproductive activity of female Thelazia corresponds with the presence/absence of the intermediate host populations. Infection is endemic in dogs. It occurs during the most intensive vector activity in the warm period of the year (19). T. callipaeda firststage larvae $\left(\mathrm{L}_{1}\right)$ can be found in the lachrymal secretions of dogs in summer (June-July), when infections of intermediate hosts occur. The evidence of fourth-stage larvae $\left(\mathrm{L}_{4}\right)$ in March-April and July-October may be accounted for by the presence of Diptera population from early spring to early autumn. The presence of immature stages in October indicates an overlapping of Thelazia generations and a second cycle of vector infection (26). The parasite remains only in the final host during winter. To produce a new infection, dipteras have to ingest the larvae of Thelazia in spring, which must remain in them for about a month to become infectious (21). Research conducted in southern Italy showed that $P$. variegata is most active during July and August, at $20-25^{\circ} \mathrm{C}$ and $50-75 \%$ relative humidity, due to which a higher number of infections caused by T. callipaeda could be expected, even in non-endemic regions (22). Special climatic conditions, suitable for the activity of the intermediate host population, are also typical of Serbia, where rains concentrate in the period of May-June, when relative humidity increases.

Serbia is a continental country, located in southeastern Europe in the middle of the Balkan Peninsula, between latitudes $41^{\circ} 53^{\prime}$ and $46^{\circ} 11^{\prime} N$ N. Given these geographic coordinates, the presence of T. callipaeda in Serbia is not surprising, since thelaziosis has been reported as endemic in many countries of the world at similar latitudes, between $39^{\circ}$ and $46^{\circ}(22)$. Serbia belongs to the region of Central Europe. Geographically and climatically, its northern regions are similar to the Pannonian basin, whereas its southern part resembles Mediterranean countries. The largest part of the territory of Serbia has a temperate continental climate, and the climate in the southwestern part is between subtropical and continental, resembling the condi- 
tions in countries where thelaziosis has been reported. The average annual rainfall for the entire country is $896 \mathrm{~mm}$. Most of the infected dogs examined in this study came from the north (Province of Vojvodina) and east of Serbia (cities of Zaječar and Bor). In northern Serbia, T. callipaeda was diagnosed in 39 dogs from an area lying at $45^{\circ} 15^{\prime}$ north latitude. The Zaječar District and the Bor District form an administrative region called Timočka krajina, with an average altitude of $353 \mathrm{~m}$ above sea level, at latitude $44^{\circ} 04^{\prime}$. The area with the second largest number of infected dogs was the Belgrade city and its vicinity. The geographical coordinates of Belgrade are consistent with the provisional geoclimatical model typical of Thelazia callipaeda, especially considering the elevation (altitude $116.75 \mathrm{~m})$ (Fig. 1).

The first isolated cases of ocular thelasiosis in dogs and cats in Serbia were diagnosed in the central, western and southern parts of the country, where only haplotype h1 of T. callipaeda was found (8). Results of our investigations on the prevalence of thelaziosis in dogs, show a relatively high prevalence in two regions in central Serbia (Belgrade suburb $-41.83 \%$ and Braničevo District $-21.68 \%$ ) and in one region in southern Serbia (Pčinja District - 25.00\%). A high prevalence of this nematodosis in dogs was also found in further two, still undiscovered epizootiologic regions in the north (43.58\% in North Banat District and 28.94\% in South Bačka District) and east of Serbia $(47.50 \%$ in Bor District and 30.92\% in Zaječar District).

These findings suggest that Serbia may be an endemic region for this nematodosis, which carries great risks for canine and human health. After the parasite had spread among domestic and wild carnivores in Europe, the first human cases of this zoonotic disease were described in Italy, France, and Serbia $(18,24)$. Although humans are competent hosts, they usually act as accidental final hosts, in whom the third-stage larvae can grow into adults, but without epidemiologic effects on parasite transmission (7). All cases of thelaziosis in humans were reported during summer, in the period of the most intensive vector activity $(19,21)$. The occurrence of thelaziosis and allergic (pollen-induced) conjunctivitis in humans in spring and summer may affect the validity of the etiological diagnosis of this disease. From the clinical point of view, the present findings indicate the epidemiological importance of this parasitosis, and its significance during the differential diagnosis of bacterial or allergic conjunctivitis.

Clinical diagnosis of canine and human thelaziosis can be difficult if only a small number of parasites are present. In such cases, clinical signs related to the inflammatory response associated with the development of third- and/or fourth-stage larvae are similar to allergic conjunctivitis (24). The final diagnosis is based on the parasites present in the conjunctival sac of the final host. First-stage larvae $\left(\mathrm{L}_{1}\right)$ can be seen when eye secretions are examined under a microscope.
T. callipaeda can be distinguished morphologically from $T$. californiensis on the basis of the number of pre- and postcloacal papillae in the male, the position of the vulva in the female, and the number of cuticle stripes $(3,6,25)$. Analysis based on the molecular characterization of T. callipaeda (SSCP single-strand conformation polymorphism) is important for the study of the population genetics of this species (30). Only one genetically identified haplotype of $T$. callipaeda circulates among dogs, cats, and foxes in Europe (haplotype 1 - h1) $(4,8,15,30)$.

This finding confirms that the species of the genus Thelazia have metazoonotic potential. Therefore, it is necessary to treat infected domestic animals, which may represent a reservoir of infection for humans. The treatment of infected dogs in this study included the mechanical removal of adult parasites from the eye, local application of antibiotics, and antiparasitic treatment. Diagnosed infections were of high-intensity, and most of Thelazia were diagnosed deep in the lower bulbar fornix, between the eyeball and the third eyelid. The antiparasitic treatment of dogs was conducted with ivermectin (s/c $0.2 \mathrm{mg} / \mathrm{kg})$ and a spot-on solution of $100 \mathrm{mg}$ imidoclopride and $25 \mathrm{mg}$ moxidectin.

The climatic conditions of Serbia are consistent with the expected geoclimatical model, and the presence of T. callipaeda in dogs in Serbia confirms that this region has optimal conditions for the activity of the intermediate vector population: dipteral species of the family Drosophilidae, genus Phortica.

The relatively high prevalence of thelaziosis caused by $T$. callipaeda in dogs $(35.52 \%)$ in some areas of Serbia indicates the endemicity of eyeworm infection in these areas. Climate changes, global warming, frequent interstate and intercontinental travel of people and animals, as well as the import of dogs from European and other countries, facilitate the spread of Thelazia species and increase the risk of infection in other dogs and humans in this region. The presence of T. callipaeda in dogs in Serbia demonstrates the need to identify the reservoirs of infection and to implement appropriate protective measures, especially in view of the biological and environmental risk factors existing in the region. The high infection rate of canine thelaziosis reported in this paper suggests that practitioners should include this eye infection among differential diagnoses of ocular diseases in dogs from the specified areas of Serbia.

In the clinics of the Faculty of Veterinary Medicine in Belgrade, we examined the effect of several spot-on products from different manufacturers (containing imidacloprid + moxydectin) applied to more than 50 dogs. We found that in the case of low-intensity infections (less than 10 parasites per eye), the mechanical removal of thelasias was unnecessary, except when the parasites were partially located in the nasolacrimal duct.

For countries with a moderate continental climate (such as Serbia) where ocular thelasiosis has not yet 
been diagnosed, it is recommended to introduce a mandatory examination of the eyes. All dogs presented to veterinary clinics should undergo a detailed ophthalmologic examination, particularly in the period of the seasonal occurrence of the parasite population and intermediate hosts.

In all dogs with symptoms of conjunctivitis, blepharitis, and keratitis, one should pay particular attention to the parasitic etiology of the changes. The aim of this screening is to interrupt the developmental cycle of the parasite, since the symptoms in animals can be identified only by the owners or ordinary veterinarians, who are responsible for removing the parasites and treatment.

Future investigations should be focused on determining the local distribution and density of the insect vector (Phortica variegata) in this geographical area. This emergent zoonosis should be included by veterinarians, physicians, and ophthalmologists in the differential diagnosis of ocular manifestations in their patients, particularly in areas where T. callipaeda is endemic, as it is in Serbia.

\section{References}

1. Anderson $R$. C.: Nematode parasites of vertebrates: their development and transmission. Guilford (UK), CABI Publishing 2000, p. 404-405.

2. Bächli G., Vilela C. R., Escher S. A., Saura A.: The Drosophilidae (Diptera) of Fennoscandia and Denmark, vol. 39. [in:] Series: Fauna Entomologica Scandinavica, Brill, Leiden, Netherlands 2005

3. Bhaibulaya M., Prasertsilpa S., Vajrasthira S.: Thelazia callipaeda Railliet and Henry 1910, in man and dog in Thailand. Am. J. Trop. Med. Hyg. 1970, 19, 476-479.

4. Calero-Bernal R., Otranto D., Perez-Martin J. E., Serrano F. J., Reina D.: First report of Thelazia callipaeda in wildlife from Spain. J. Wild. Dis. 2013, 49, 458-460

5. Caron Y., Premont J., Losson B., Grauwels M.: Thelazia callipaeda ocular infection in two dogs in Belgium. J. Small. Anim. Pract. 2013, 54, 205-208.

6. Choi W. Y., Youn J. H., Nam H. W., Kim W. S., Kim W. K., Park S. Y., Oh Y. W. Scanning electron microscopic observations of Thelazia callipaeda from human. Korean J. Parasitol. 1989, 27, 217-223.

7. Fuentes I., Montes I., Saugar M. J., Latrofa S., GárateT., Otranto D.: Thelaziosis in humans, a zoonotic infection, Spain. Emerg. Infect. Dis. 2011, 12, 2073-2075.

8. Gajić B., Bogunović Danica, Stevanović J., Kulišić Z., Simeunović P. Stanimirovic $Z$.: Canine and feline thelaziosis caused by Thelazia callipaeda in Serbia. Acta Veterinaria-Beograd 2014, 64, 447-455.

9. Hermosilla C., Herrmann B., Bauer C.: First case of Thelazia callipaeda infection in a dog in Germany. Vet. Rec. 2004, 154, 568-569.

10. Hodžić A., Latrofa S. M., Annoscia G., Ali A., Beck R., Lia P. R., Dantas-Torres F., Otranto D.: The spread of zoonotic Thelazia callipaeda in the Balkan area. Parasites \& Vectors 2014, 7, 352.

11. Liu Guo-Hua, Gasser B. R., Otranto D., Xu Min-Jun, Shen Ji-Long, Mohandas N., Zhou Dong-Hui, Zhu Xing-Quan: Mitochondrial genome of the eyeworm, Thelazia callipaeda (Nematoda: Spirurida), as the first representative from the family Thelaziidae. PLOS Neglected Trop. Dis. 2013, 7, 2029.

12. Mahanta J., Alger J., Bordoloi P.: Eye infestation with Thelazia species. Indian J. Ophthalmol. 1996, 44, 99-101.

13. Maia C., Catarino A. L., Almeida B., Ramos C., Campino L., Cardoso L.: Emergence of Thelazia callipaeda infection in dogs and cats from east-central Portugal. Transbound Emerg. Dis. Nov 8. doi: 10.1111/tbed. 12284, 2014.

14. Malacrida F., Hegglin D., Bacciarini L., Otranto D., Nägeli F., Nägeli C. Bernasconi C., Scheu U., Balli A., Marenco M., Togni L., Deplazes P. Schnyder M.: Emergence of canine ocular thelaziosis caused by Thelazia callipaeda in southern Switzerland. Vet. Parasitol. 2008, 157, 321-327.

15. Mihalca D. A., D’Amico G., Scurtu I., Chirilă R., Matei A. I., Ionică M. A.: Further spreading of canine oriental eyeworm in Europe: first report of Thelazia callipaeda in Romania. Parasit. Vectors. 2015, 8, 48

16. Miró G., Montoya A., Hernández L., Dado D., Vázquez M. V., Benito M. Villagrasa M., Brianti E., Otranto D.: Thelazia callipaeda infection in dogs: a new parasite for Spain. Parasit. Vectors 2011, 27, 148.
17. Motta B., Nägeli F., Nägeli C., Solari-Basano F., Schiessl B., Deplazes P., Schnyder M.: Epidemiology of the eye worm Thelazia callipaeda in cats from southern Switzerland. Vet. Parasitol. 2014, 203, 287-293.

18. Otašević S., Trenkić Božinović M., Tasić A., Petrović A., Petrović V.: Thelazia callipaeda and Eye Infections. Acta Fac. Med. Naiss. 2014, 31, 171-176.

19. Otranto D., Brianti E., Cantacessi C., Lia R. P., Maca J.: The zoophilic fruit fly Phortica variegata: morphology, ecology and biological niche. Med. Vet. Entomol. 2006a, 20, 358-364

20. Otranto D., Cantacessi C., Mallia E., Lia R. P.: First report of Thelazia callipaeda (Spirurida, Thelaziidae) in wolves in Italy. J. Wild. Dis. 2007, 43, 508-511

21. Otranto D., Cantacessi C., Testini G., Lia R. P.: Phortica variegata as an intermediate host of Thelazia callipaeda under natural conditions: evidence for pathogen transmission by a male arthropod vector. Int. J. Parasitol. 2006, $36,1167-1173$.

22. Otranto D., Dantas-Torres F., Brianti E., Traversa D., Petrić D., Genchi C. Capelli G.: Vector-borne helminths of dogs and humans in Europe. Parasit. Vectors 2013, 6, 16.

23. Otranto D., Dantas-Torres F., Mallia E., Di Geronimo P. M., Brianti E., Testini G., Traversa D., Lia R. P.: Thelazia callipaeda (Spirurida, Thelaziidae) in wild animals: report of new host species and ecological implications. Vet. Parasitol. 2009, 166, 262-267.

24. Otranto D., Dutto M.: Human thelaziasis, Europe. Emerg. Infect. Dis. 2008, 14, 647-649.

25. Otranto D., Ferroglio E., Lia R. P., Traversa D., Rossi L.: Current status and epidemiological observation of Thelazia callipaeda (Spirurida, Thelaziidae) in dogs, cats and foxes in Italy: a "coincidence" or a parasitic disease of the Old Continent? Vet. Parasitol. 2003a, 116, 315-325

26. Otranto D., Lia P. R., Buono V., Traversa D., Giangaspero A.: Biology of Thelazia callipaeda (Spirurida, Thelaziidae) eyeworms in naturally infected definitive hosts. Parasitol. 2004, 129, 627-633.

27. Otranto D., Lia R. P., Cantacessi C., Testini G., Troccoli A., Shen J. L., Wang $Z$. $X$ : Nematode biology and larval development of Thelazia callipaeda (Spirurida, Thelaziidae) in the drosophilid intermediate host in Europe and China. Parasitol. 2005b, 131, 847-855

28. Otranto D., Lia R. P., Testini G., Milillo P., Shen J. L., Wang Z. X.: Musca domestica is not a vector of Thelazia callipaeda in experimental or natural conditions. Med. Vet. Entomol. 2005, 19, 135-139.

29. Otranto D., Lia R. P., Traversa D., Giannetto S.: Thelazia callipaeda (Spirurida, Thelaziidae) of carnivores and humans: morphological study by light and scanning electron microscopy. Parassitologia 2003, 45, 125

30. Otranto D., Testini G., De Luca F., Hu M., Shamsi S., Gasser R. B.: Analysis of genetic variability within Thelazia callipaeda (Nematoda: Thelazioidea) from Europe and Asia by sequencing and mutation scanning of the mitochondrial cytochrome c oxidase subunit 1 gene. Mol. Cell. Probes 2005a, 19, 306-313.

31. Otranto D., Traversa D.: Thelazia eyeworm: an original endo- and ecto-parasitic nematode. Trends Parasitol. 2005, 21, 1-4

32. Price $E$. $W .:$ A new nematode parasitic in the eyes of dogs in the United States. J. Parasitol. 1930, 17, 112-113.

33. Railliet A., Henry A.: Nouvelles observations sur les Thelazies, nematodes parasites de l'oeil. Compt. Rend. Soc. Biol. 1910, 68, 783-785.

34. Ruytoor P., Dean E., Pennant O., Dorchies P., Chermette R., Otranto D., Guillot J.: Ocular thelaziosis in dogs, France. Emerg. Infect. Dis. 2010, 16 1943-1945.

35. Shen J. L., Gasser R. B., Chu D., Wang Z. X., Yuan X., Cantacessi C.: Human thelaziosis: a neglected parasitic disease of the eye. J. Parasitol. 2006, 92, 872$-875$

36. Shi Y. E, Han J. J., Yang W. Y., Wei D. X.: Thelazia callipaeda (Nematoda: Spirurida): Transmission by flies from dogs to children in Hubei, China. Trans. R. Soc. Trop. Med. Hyg. 1988, 82, 627.

37. Soares C., Ramalho Sousa S., Anastacio S., Goreti Matias M., Marques I., Mascarenhas S., Joao Vieira M., de Carvalho L. M., Otranto D.: Feline thelaziosis caused by Thelazia callipaeda in Portugal. Vet. Parasitol. 2013, 196, 528-531.

38. Vieira L., Rodrigues T. F., Costa A., Diz-Lopes D., Machado J., Coutinho T., Tuna J., Latrofa S. M., Cardoso L., Otranto D.: First report of canine ocular thelaziosis by Thelazia callipaeda in Portugal. Parasit. Vectors 2012, 5, 124.

39. Wang Z. X., Hu Y., Shen J. L., Wang K. C., Wang H. Y., Jiang B. L., Zhao P. Wang Z. C., Ding W., Wang F., Xia X. F.: Longitudinal investigation and experimental studies on thelaziosis and the intermediate host of Thelazia callipaeda in Guanghua country of Hubei province. Zhonghua Liu Xing Bing Xue Za Zhi 2003, 24, 588-590

40. Zakir R., Zhong-Xia Z., Chioddini P., Canning C. R.: Intraocular infestation with the worm, Thelazia callipaeda. Br. J. Ophthalmol. 1999, 83, 1194-1195.

Corresponding author: Stepanović Predrag Ph.D., assoc. prof., Faculty of Veterinary Medicine, University of Belgrade, Department for Equine, Small Animal, Poultry, and Wild Animal Diseases, Bulevar Oslobodjenja 18, 11000 Belgrade, SERBIA, e-mail: pedja@vet.bg.ac.rs, \& prestepanovic@gmail. com, cell: $+\mathbf{3 8 1 6 3 2 1 5 1 4 9}$ 